\title{
Predictors of attitude towards HIV counselling and testing among secondary school teachers in Akinyele LGA, Ibadan metropolis, Oyo state of Nigeria
}

\author{
Adam O. Yusuf ${ }^{1,2}$, Ajibola A. Ishola ${ }^{1}$ \\ ${ }^{1}$ Department of Psychology, University of Ibadan, Ibadan, Nigeria \\ ${ }^{2}$ Department of Guidance and Counselling, University of Ibadan, Ibadan, Nigeria
}

\begin{abstract}
Introduction: Human immunodeficiency virus (HIV) counselling and testing (HCT) is recognized as a critical component of HIV prevention. However, what is of serious concern is the low uptake of HCT among teachers due to issues related to psychosocial factors, whose role has not been examined in the extant literature. This study examined the relationship between psychosocial factors (stigma, perceived barriers, knowledge, belief) and attitude towards HIV counselling and testing among secondary school teachers in Ibadan, Oyo State.
\end{abstract}

Material and methods: The study had a cross-sectional design. Participants (350) were sampled from selected secondary schools through stratified sampling technique. The mean age was $45.68(\mathrm{SD}=7.72)$, $57 \%$ were female with 11.23 ( $\mathrm{SD}=3.42$ ) years of experience. A self-report questionnaire containing a standardized instrument was used in the collection of data. Data were analysed using descriptive, multiple regression analysis and Pearson product moment correlation at $p \leq 0.05$.

Results: The findings revealed that anticipated stigma $(r=-0.39)$, belief $(r=0.23)$, level of knowledge $(r=0.30)$, and perceived barriers $(r=-0.46)$ correlated significantly with attitude towards HIV counselling and testing among teachers. Perceived barriers $(\beta=-0.43, t=-5.56, p=0.00)$, anticipated stigma $(\beta=-0.27, t=4.93, p=0.00)$, knowledge $(\beta=0.26, t=4.38, p=0.00)$ and belief $(\beta=0.20, t=2.69$, $p=0.00)$ predicted attitude towards HIV counselling and testing.

Conclusions: This study confirms that anticipated stigma, knowledge and perceived barriers to HIV testing influenced attitude towards HCT among teachers. The Health Ministry was advised to provide community-based counselling outreach programmes for teachers, especially those in rural areas.

HIV AIDS Rev 2021; 20, 3: 208-212

DOI: https://doi.org/10.5114/hivar.2021.109624

Key words: knowledge, stigma and discrimination, perceived barrier, religious belief, attitude towards HIV counselling and testing.

Address for correspondence: Ajibola A. Ishola, Department of Psychology, University of Ibadan, Ibadan, Nigeria,

e-mail: ajibola_ishola@yahoo.co.uk
Article history:

Received: 18.11.2020

Received in revised form: 16.12 .2020

Accepted: 02.03.2021

Available online: 30.08 .2021
International Journal of HIV-Related Problems

HIV \& AIDS

R e v i e w 


\section{Introduction}

Nigeria is a one of the leading countries with a regrettably high incidence of people living with human immunodeficiency virus (HIV)/acquired immunodeficiency syndrome (AIDS) in the West and Central Africa Sub-region [1]. Statistics indicated that at the start of 2017, about 6.1 million adults and children within the west and central geographic area had contracted HIV. Also, 280,000 million people from these regions died from AIDS whereas 5 million children were orphaned in the regions as a result of HIV/AIDS. Specifically, as at the start of 2017, Nigeria had about 3.1 million people living with HIV/AIDS, 150,000 died of AIDS and a $2.8 \%$ infection prevalence rate $[2,3] .80 \%$ of HIV new infections in Nigeria were contracted through heterosexual activities through other sources [2]. In Nigeria, the HIV/AIDS pandemic is influenced by deficient knowledge about health, non-provision of HIV testing and counselling families, undesirable social practices and a weak health care system $[2,3]$.

HIV/AIDS counselling is a psycho-social intervention of preventing the transmission, spread and arresting the impact of HIV/AIDS [4]. HIV/AIDS testing includes an investigation of an individual's blood so as to decide his/ her HIV/AIDS status. HIV/AIDS advising and testing help both uninfected persons and patients to understand themselves, and re-adapt viably to life challenges and contribute genuinely to the advancement of society [3]. HIV counselling and testing (HCT) assumes a crucial role in HIV/AIDS treatment that includes basic prevention, preventing mother-to-baby transmission, antiretroviral treatment, the treatment of HIV-related ailments, tuberculosis control and psychosocial support [4]. HIV/AIDS counselling consists of 3 stages, which are pre-test, post-test and follow-up sessions [5]. Given the importance of HCT, the utilisation of voluntary counselling and testing (VCT) service in Nigeria is still poor. Data from UNAIDS (2017) indicated that in 2016, only $34 \%$ of people living with HIV/AIDS (PLWHA) knew their status. Across Nigeria, the VCT rates were $15.1 \%$ for the population between the ages of 15 and 49 in a period of 12 months in 2017 [2]. Recently the Family Life and HIV Educational programme has been included in the secondary school curriculum. In 2015, more than 48,500 schools had access to lessons relating to HIV, transmission, prevention and barriers influencing it such as stigma and gender-based violence [2].

Generally, the teacher, when compared to the general adult population in Nigeria, demonstrates better knowledge about HIV/AIDS [7, 8]. The Nigerian studies also revealed that teachers were well exposed to knowledge of necessity for counselling and testing as a preventive measure against HIV/AIDS infection [7, 8]. The teachers are equally aware of barriers to HCT and knowledge surrounding it [7, 8]. Despite the level of awareness, and knowledge, attitude towards HCT is still poor and the perceived barriers still high among the teachers. Current studies on predictors of VCT rates have focused mostly on students and adolescents in second- ary schools. There is a need to address factors influencing attitude towards HCT among secondary school teachers in Nigeria.

There are a variety of factors which will influence the HIV/AIDS guidance and testing pattern among the people, one of which is the social stigma factor: It manifests in shunning, social distancing, coercion and non-supportiveness, and self-stigma results in reduced or diminished vanity. Disapproval will cause damaging thoughts, behaviours and actions on the part of people and groups [9]. The stigma and discrimination related to HIV/ AIDS have been conceived at two levels: social group and individual. At the social group or cultural level, it manifests in discriminatory laws, policies, widespread discourse and social conditions of individuals living with HIV/AIDS. At the individual level, it takes the shape of behaviours, thoughts and feelings that represent unfairness against persons infected with HIV. The first targets of HIV/AIDS stigma are people with HIV and people who appeared to be infected [9].

Another factor of interest is the low level knowledge. Information of different aspects of HIV/AIDS enables a proper move to be made in connection with avoidance of HIV and decrease in the spread of HIV $[10,11]$. The assumption of this approach was that knowledge of HIV risk behaviours would result in HIV preventative behaviours [10]. However, the increasing incidence of HIV infection among the population exposed suggests that HIV knowledge is necessary but not sufficient for HIV risk reduction [11]. What is unknown is the extent to which knowledge influences the behaviour of teachers in rural schools. When people are knowledgeable about HCT they live a careful life and help people in reducing the spread of the virus.

Lastly, another factor of interest is cultural belief. Negative cultural practices such as cultural belief, fatalism such that an individual has the belief that nothing can prevent death or infection (we are at the mercy of nature) and this makes them venture into reckless behaviour that is detrimental to their health such as having unprotected sexual intercourse with multiple partners. Also practices such as widow betrothal, sexual molestation, unprotected sex and liquor ingestion have been implicated in HIV testing services $[2,12]$. Given this gap, this study intends to determine how anticipated stigma, negative perception, cultural belief and level of knowledge correlate with HIV counselling and testing and among secondary school teachers. The broad aim of this research is to determine the correlates of HIV counselling and testing behaviour among secondary school tutors in Ibadan city. Specifically the study investigates the following objectives: 1) to investigate if the independent variables (anticipated stigma, religious belief, level of knowledge and perception or barrier) will be significant correlates of the dependent variable (attitude towards HCT among teachers); 2) to examine the contribution of anticipated stigma, religious belief, level of knowledge and perception or barrier to the prediction of attitude towards HIV counselling and testing among teachers. 


\section{Material and methods}

The current work is a cross-sectional study of the correlational method design. The form of inquiry was accepted by the State Ministry of Health Ethics Committee (AD $13 / 479 / 14 / 343 B$ ). There was a short study description for each participant, and those willing to participate agreed to an informed consent form before the questionnaire was administered to them.

\section{Participants}

A cross-sectional study of secondary school teachers in 20 selected secondary schools under the Akinyele Local Government Area in the Ibadan metropolis, Oyo State, Southwestern, Nigeria, was performed. Three hundred and fifty teachers were selected from the population of teachers (559) in Akinyele Local Government Area in the Ibadan metropolis of Oyo state. Stratified sampling technique was used to select the sample size from the population of the study. A majority of the participants were female $(57 \%)$ with the mean age of $35.68(\mathrm{SD}=7.72)$ with 11.23 $(\mathrm{SD}=3.42)$ years of experience on average. Permission was obtained from the school management authorities of the selected schools and oral informed consent was obtained from the participants to participate in the study. Copies of the questionnaire were administered to the participants at the sampled schools assisted by research assistants. The data were collected between $1^{\text {st }}$ of June 2019 and 30 August, 2019. The data were analysed in September 2019.

\section{Instruments}

The questionnaire contains items on socio-demographic characteristics and standardized scales measuring the variables on interest in the study. HIV counselling and testing behaviour was captured with the 16-item Attitude towards HIV counselling and testing scale by Kalichman and Simbayi $(\alpha=0.78)$ [13]. Sample items include "I do not need to undergo HCT testing" and "testing for HIV is important because one can plan for the future". The reliability coefficient $=0.82$. Anticipated HIV stigma was measured with the 10-anticipated stigma scale developed by Nyblade et al. [14] (reliability co-efficient $=0.89$ ). Items asked information about how a participant would react to specific adverse outcomes if other individuals knew their HIV status (e.g., I will feel stressed that people would avoid me in a party if individuals knew about my HIV status). The reliability coefficient $=0.76$. The knowledge of HCT was captured with the 15-item scale developed by Zhang et al. [15]. Based on Cronbach's alpha, reliability reported ranged from 0.77 to 0.83 , and a reliability coefficient of 0.75 was obtained in the present study. Teachers' religious belief was assessed with the 10-item Religious Belief Scale (RBS) adopted from Chiang et al. [16] ( $\alpha=0.73)$. This scale measures perceived status of religious belief (i.e. I love to share my religious beliefs with others). Perceived Barriers to HCT was measured with the 10-item scale adapted from Cooke et al. [17]. Sample item: "I am afraid of my privacy/anonymity when I go to the clinic" ( $\alpha=0.85)$. All the questionnaire items were scored in a Likert-response format ranging from strongly agree (5) to strongly disagree (1). The questionnaire takes an average of 10 minutes to complete and the administration was done during school hours in teachers' staff rooms.

\section{Data analysis}

The program SPSS version 22 was used to evaluate the results. The data generated in the study were analysed using descriptive statistics, multiple regression analysis and Pearson product moment correlation (PPMC) at $p \leq 0.05$ significance level.

\section{Results}

The results revealed that of teachers participating in this study $57 \%$ were female. The mean age was $35.68(\mathrm{SD}=7.72)$. $36.67 \%$ were National Certificate of Education (NCE) certificate holders, 23\% were Ordinary National Diploma (OND) certificate holders, $22.5 \%$ had Bachelor degrees and 21.33\% were Master's degree holders. The average number of years of experience was 11.23 ( $\mathrm{SD}=3.42$ ) years. $10.33 \%$ had less than one year of experience, $9.67 \%$ had acquired $1-5$ years of experience, $48.33 \%$ had 6-10 years of experience, and $31.67 \%$ had worked for more than 10 years in the teaching profession.

The first objective, which was to investigate whether the independent variables (anticipated stigma, religious belief, level of knowledge and perception or barrier) were significant correlates of the dependent variable (attitude HCT

Table 1. Correlation analysis showing the relationship between psycho-social variables and HIV counselling and testing

\begin{tabular}{|c|c|c|c|c|c|c|}
\hline Variable & Mean & SD & $n$ & $r$ & $p$ & Remark \\
\hline Attitude towards HIV counselling and testing & 45.6840 & 7.72417 & & & & \\
\hline Stigma and discrimination & 26.3000 & 8.80364 & 350 & $-0.297^{\star *}$ & 0.000 & Sig. \\
\hline Religious belief & 31.1400 & 6.85070 & 350 & $0.234^{* *}$ & 0.000 & Sig. \\
\hline Level of knowledge & 49.9000 & 8.85050 & 350 & $0.393^{* *}$ & 0.000 & Sig. \\
\hline Perceived barrier to HCT & 25.2960 & 11.23143 & 350 & $-0.455^{* *}$ & 0.000 & Sig. \\
\hline
\end{tabular}

\footnotetext{
**Significant at 0.05 level
} 
Table 2. Multiple regression analysis showing contribution of independent variables to the prediction of HIV counselling and testing

\begin{tabular}{l|c|c|c|c|c}
\hline Model & B & S.E. & $\boldsymbol{\beta}$ & T & Sig. \\
\hline Constant & 26.41 & 4.010 & & 6.580 & 0.000 \\
\hline Sigma and discrimination & -0.236 & 0.048 & -0.269 & -4.929 & 0.000 \\
\hline Belief & 0.222 & 0.083 & 0.197 & 2.692 & 0.008 \\
\hline Level of knowledge & 0.223 & 0.051 & 0.255 & 4.375 & 0.000 \\
\hline Barrier or perception toward seeking HCT & -0.295 & 0.053 & -0.428 & -5.564 & 0.000 \\
\hline
\end{tabular}

$R=0.574, R^{2}=0.329$, Adjusted $R^{2}=0.318$. Standard error of the estimate $=6.37829, F(4,345)=30.042, p=0.000$. Dependent variable $=$ HIV counselling and testing behaviour

among teachers), was analysed using PPMC analysis, and the summary results are in Table 1.

As shown in Table 1, the results demonstrated that anticipated stigma $(r=-0.30, p<0.05)$, religious belief $(r=0.23$, $p<0.05)$, level of knowledge $(r=0.39, p<0.05)$, perception or barrier in seeking HCT $(r=-0.46, p<0.05)$ were significant correlates of attitude towards HIV counselling and testing. The results show that religious belief and level of knowledge about HIV/AIDS were associated with positive attitude towards HIV counselling and testing in the study. Also, anticipated stigma and barrier in seeking HCT were associated with negative or declining positive attitude towards HIV counselling and testing in the study.

The second objective examined the contribution of anticipated stigma, religious belief, level of knowledge and perceived barriers to the prediction of attitude towards HIV counselling and testing among teachers. This objective was analysed using multiple regression analysis and the results are presented in Table 2.

The results in Table II show that $R=0.57, R^{2}=0.33$ and adjusted $R^{2}=0.32$, which implies that $31.8 \%$ is accounted for by the combination of anticipated stigma, perceived barriers toward seeking HCT, level of knowledge and religious belief of people. This indicates that other factors outside the scope of this study accounted for $32 \%$ of the total variance of attitude towards HIV counselling and testing. The analysis also shows that the F-ratio value of $(\mathrm{F}=30.04$, $p<0.05)$ was significant. The result shows that perceived barriers toward seeking HCT has the highest contribution to attitude towards HIV counselling and testing with a beta weight of -0.43 and $t$-value of 5.56 , followed by anticipated stigma with a beta weight of -0.27 and t-value of 4.93 , followed by level of knowledge with a beta weight of 0.26 and $t$-value of 4.375 . This is followed by religious belief of people with beta weight of 0.20 and $t$-value of 2.69 . In conclusion, all the independent variables were significant predictors of HCT.

\section{Discussion}

Based on the results analysed, the study confirmed that a converse relationship exists between anticipated stigma and HIV counselling and testing among secondary school teachers in Ibadan. Also, anticipated stigma predicted HIV counselling and testing among the respondents. These findings are in line with Khalifa and Eltyeb [1], who found that the decision to go for HCT was significantly influenced by the social response of perceived severity of anticipated stigma. According to Goffman [24] stigma and social separation have turned into the disastrous results of the HIV malady such that many alluded to AIDS stigmatisation as the third pandemic. The major obstacle faced by the numerous HIV/ AIDS programmes remains the issue of stigma and social distancing [18].

The result of the second relationship on the association between religious belief and HIV counselling and testing demonstrated that there was a significant relationship between religious belief and HIV counselling and testing among secondary school teachers in Ibadan. This supports Trinitapoli's finding [19] that religious beliefs were associated with perception of the HIV/AIDS services.

The result of testing for the third association, between level of knowledge on HIV and HIV counselling and testing, was confirmed. A strong association was found between knowledge on HIV and HIV counselling and testing among teachers in Ibadan. This finding supports the observation by Achalu and Udo that HIV knowledge was associated with HCT testing intentions [10]. The finding was in contrast with Beyene, who found that Ethiopian and Eritrean immigrants were afraid to discuss HIV with their friends and deny their personal HIV risky behaviours even though their level of HIV awareness was high [20].

The result on the relationship between perceived barrier to HCT and attitude towards HIV counselling and testing decisions was supported. It was found that there was a significant inverse relationship between perceived barrier to HCT and attitude towards HIV counselling and testing among secondary school teachers in Ibadan. This finding supports the finding of Tracy Tross and Vlahov [21] that low-risk discernment is additionally connected contrarily to the goal of going for HCT; if individuals trust that they are not in danger of HIV/AIDS, it looks bad to them to go for HCT. Then again, an empirical study likewise demonstrated that a high risk of vulnerability is one of the fundamental motivations for individuals to go for HCT $[22,23]$. 


\section{Conclusions}

This study concluded that attitude and utilisation of HCT services by teachers are related to individual, social, religious and economic factors. As in other HCT services in the developing world, the findings from this study have many implications. Secondary school teachers do not visit HIV counselling and testing centres due to the anticipated stigmatisation and discrimination they are bound to experience. Poor knowledge and faulty cultural attitudes were found to induce high resistance and refusal to go for HIV/ AIDS testing and counselling. Therefore, this study suggests that intensive orientation and re-orientation of health workers and stakeholders in the health sector concerning effective HIV counselling and testing for secondary school teachers should be implemented. Towards this end, counsellors and all other helping professionals must be alert and sensitive to these growing trends. There is a need to put more emphasis on community-based programmes to reach many teachers, especially in rural areas. Establishment of the care and support component in the available HCTs will serve secondary school teachers who test positive in the rural areas.

Further research is necessary in order to investigate other inhibiting factors responsible for uptake of HIV/AIDS counselling and testing across other states in the country in order to expand the generalisation of the findings of this study. More subjective and quantitative investigations ought to be directed in other urban territories with members from both comparable and diverse populations. Along these lines, the outcomes acquired in this study might be assessed as regards their transferability to different settings.

\section{Acknowledgements}

The authors wish to thank all the participants of this study for their valuable cooperation and participation.

\section{Conflict of interest}

The authors have no conflict of interest.

\section{References}

1. Khalifa AFM, Eltyeb EM. HIV voluntary counselling and testing utilisation using health belief model among university students in Sudan. Int J Public Health Res 2015; 3: 357-359.

2. AVERT.ORG. HIV and AIDS in Nigeria. 2018. Available at: https:// www.avert.org/professionals/hiv-around-world/sub-saharan-africa/nigeria (Accessed: 17.12.2018).

3. UNAIDS 'AIDSinfo'. Available at: http://aidsinfo.unaids.org/ (Accessed: 17.12.2018).

4. Idogho O. Determinants of voluntary HIV counselling and testing uptake in the federal capital territory Abuja, Nigeria. Abuja: University Of South Africa; 2010.

5. Yahaya LA, Jimoh AA, Balogun OR. Factors hindering acceptance of HIV/AIDS voluntary counseling and testing (VCT) among youth in Kwara State, Nigeria. Afr J Reprod Health 2010; 14: 159-164.

6. Rosenberg NE, Hauser, BM, Ryan J, Miller WC. The effect of HIV counselling and testing on HIV acquisition in sub-Saharan Africa: a systematic review. Sex Trans Infect 2016; 92: 579-586.
7. Oyewale TO. HIV/AIDS knowledge and attitude among teachers in Abjua, Nigeria. Thesis. Africa: University of South Africa. Available at: http://uir.unisa.ac.za/bitstream/10500/2125/1/dissertation.pdf (Accessed: August 2018).

8. Uti O, Sofola OO. Preventing HIV/AIDS through education: the role of primary and secondary school teachers in Nigeria. Nig Dent J 2013; 21: 51-55.

9. Ayiga N, Nambooze H, Nalugo S, Kaye D, Katamba A. The impact of HIV/AIDS stigma on HIV counseling and testing in a high HIV prevalence population in Uganda. Afr Health Sci 2013; 13: 278-286.

10. Achalu D, Udo H. HIV counseling and testing services in university of Uyo Youth Friendly Centre: impact of students' knowledge and perception of HIV and AIDS. Adv Soc Sci Res J 2018; 5. DOI: http://dx.doi.org/10.14738/assrj.57.4706.

11. Obiako OR, Muktar HM, Mamman AI, Sheikh TL, Tabi-Ajayi E, Obiako CO. Sexual behavior, awareness of HIV/AIDS, and attitudes of unmarried tertiary school students to HIV counseling \& testing: implications for control of HIV transmission. Adv Trop Med Public Health Int 2012; 2: 109-123.

12. Gbenda BA, Amali AO, Atser CI. Perceived influence of cultural practices on transmission of HIV/AIDS in Benue state: counselling interventions. Int J Innov Psychol Soc Dev 2018; 6: 120-129.

13. Kalichman SC, Simbayi LC. HIV testing attitudes AID stigma and voluntary HIV counselling and testing in black township in Cape Town, South Africa. Sex Transm Infect 2003; 76: 442-447.

14. Nyblade L, MacQuarrie K, Phillip F, et al. Working report measuring HIV stigma: results of a field test in Tanzania. USAID. Available at: https://sarpn.org/documents/d0001871/11-Tanzania_ USAID_June2005_Full.pdf (Accessed: 28.06.2018).

15. Zhang T, Zhang J, Gao M, He N, Detels R. Knowledge, attitudes and practices of voluntary HIV counselling and testing among rural migrants in central China: a cross-sectional study. Euro J Public Health 2011; 22: 192-197.

16. Chiang YC, Lee HC, Chu TL, Han CY, Hsiao YC. Psychometric testing of a religious belief scale. J Nurs Res 2017; 25: 419-428.

17. Cooke IJ, Jeremiah RD, Moore NJ, et al. Barriers and facilitators toward HIV testing and health perceptions among African-American men who have sex with women at a South Side Chicago Community Health Center: a pilot study. Front Public Health 2017; 4: 286.

18. Olley BO, Ogunde MJ, Oso PO, Ishola A. HIV-related stigma and self-disclosure: the mediating and moderating role of anticipated discrimination among people living with HIV/AIDS in Akure Nigeria. AIDS Care 2016; 28: 6 .

19. Trinitapoli J. AIDS \& religious life in Malawi: rethinking how population dynamics shape culture. Population-e 2015; 70: 265-293.

20. Beyene Y. Potential HIV risk behaviors among Ethiopians and Eritreans in the diaspora: a bird's eye view. Northeast African Studies 2000; 7: 119-142.

21. Tross Vlahov T. United Nations general assembly special session on HIV and AIDS (UNGASS) 2010 country report - Kenya. Nairobi. Kenya: Office of the President/National AIDS Control Council; 2006.

22. Kellerman SE, Lehman JS, Lansky A, et al. HIV testing within at risk populations in the United States and reasons for seeking or avoiding HIV testing. J AIDS 2002; 31: 202-210.

23. van Dyk AC, van Dyk PJ. "What is the point of knowing?": Psychosocial barriers to HIV/AIDS Voluntary Counselling and Testing programmes in South Africa. S Afr J Psychol 2003; 33: 118-125.

24. Goffman E. Stigma notes on the management of spoiled identity. London: Penguin; 1963.

25. World Medical Association. World Medical Association Declaration of Helsinki: ethical principles for medical research involving human subjects. Bulletin of the World Health Organization 2001; 79: 373-374. Available at: https://www.who.int/bulletin/archives/79\%284\%29373.pdf. 